\title{
Construção de política de comunicação em instituições de educação profissional, científica e tecnológica: uma proposta com base na experiência do IFSC
}

\begin{abstract}
RESUMO
Este artigo é fruto de uma pesquisa sobre a construção da Política de Comunicação do Instituto Federal de Santa Catarina (IFSC). A experiência do IFSC é descrita como uma aprendizagem organizacional impulsionadora de uma mudança estratégica. A fim de compreender o processo ocorrido, foi realizada uma pesquisa quali-quantitativa que permitiu propor ações de melhorias ao processo de construção e atualização de políticas de comunicação em instituições de educação profissional, científica e tecnológica. A experiência do IFSC revela que processos dessa natureza devem envolver uma construção coletiva, com o apoio da Alta Administração, uma vez que só assim a comunicação passa a ser entendida como um compromisso de todos os colaboradores e incorporada como estratégica na rotina organizacional.
\end{abstract}

Palavras-chave: Política de comunicação. Comunicação organizacional. Aprendizagem organizacional. Mudança estratégica. 


\section{INTRODUÇÃO}

A nova postura organizacional referente à comunicação leva as instituições a reconhecerem que ações isoladas de comunicação já não produzem o efeito necessário. Mais do que incorporar a comunicação à gestão, é necessário fazer a própria gestão da comunicação. Na atual conjuntura econômica, em que os avanços da ciência e as inovações tecnológicas permeiam as relações políticas e comerciais, faz-se necessária a formulação de uma política de comunicação organizacional que assegure a qualquer organização a transparência de suas ações aos seus públicos, permitindo ao mesmo tempo construir uma imagem favorável da própria organização, tornando-a competitiva nesse mercado de economia globalizada (CARISSIMI, 2001).

Não é simples nem rápido construir uma política de comunicação legitimada por toda uma organização com base em uma construção coletiva. O processo exige vontade política, comprometimento de todos os setores e um esforço conjunto dos profissionais envolvidos. É por isso que poucas instituições se dispõem a investir recursos em um projeto dessa natureza.

Diversos motivos podem levar uma organização a perceber a necessidade de construir uma política de comunicação. Entre elas, Bueno (2009) cita a vontade de aumentar a visibilidade da organização na mídia, melhorar o relacionamento com os públicos de interesse, consolidar a imagem ou a reputação e realizar uma alteração profunda na comunicação interna.

Foi diante de um contexto de mudanças e expansão da estrutura organizacional que o Instituto Federal de Santa Catarina (IFSC) decidiu, em 2012, construir sua política de comunicação. O Ministério da Educação (MEC) não possui uma política de comunicação própria, nem diretrizes para orientar instituições a ele vinculadas - como é o caso do IFSC. As instituições que integram a Rede Federal de Educação Profissional, Científica e Tecnológica (EPCT) - da qual o IFSC faz parte possuem políticas de comunicação obscuras pelo fato de não estarem claramente definidas ou de não terem sido construídas coletivamente. Diante dessa realidade, essas instituições enfrentam a dificuldade de gerir o processo de comunicação de uma estrutura multicampi e com públicos de interesses variados.

Para construir a sua Política de Comunicação, o IFSC contratou um consultor externo no fim de 2012 e iniciou um processo pioneiro - tanto para a organização quanto para o setor educacional. Assumido como um macroprojeto institucional, a construção da Política de Comunicação do IFSC gerou um movimento inédito na instituição: o de se pensar a comunicação como estratégica para o seu funcionamento.

A condução do processo na instituição foi feita por um grupo de pessoas integrantes da Comissão da Política de Comunicação do IFSC - criada por meio de portaria -, formada por servidores da Diretoria de Comunicação (Dircom) e com representação dos campi. Desde a primeira reunião até a aprovação do documento nas instâncias normativas, consultivas e deliberativas da Instituição, e o lançamento da Política para a comunidade interna, foram cerca de nove meses.

O processo envolveu todos os servidores e proporcionou a sistematização de percepções sobre a comunicação feita pelo Instituto e como esta poderia ser melhorada. A possibilidade de participação coletiva deu legitimidade ao processo na mesma medida em que o tornou mais complexo e rico no seu andamento. Mais do que um procedimento administrativo, o projeto organizacional de construção da Política de Comunicação do IFSC pode ser analisado como uma aprendizagem organizacional e uma busca por uma mudança estratégica na forma de enxergar a comunicação dentro de uma instituição de ensino, incorporando-a na prática organizacional.

O processo foi complexo, uma vez que não existem referências metodológicas para a construção de políticas de comunicação em instituições de ensino, em particular, entre as integrantes da Rede Federal de EPCT. Por ter sido pioneiro, o IFSC enfrentou dificuldades e precisou encontrar maneiras durante o processo para atingir o objetivo proposto. A falta de entendimento da necessidade de se estabelecer uma Política de Comunicação - construída coletivamente - e dos resultados que ela pode trazer foi mais um desafio do projeto que não se encerrou após a publicação dos princípios de comunicação. Desde o momento em que a Política foi lançada, em setembro de 2013, já foi prevista a avaliação sistemática e permanente do documento, processo já incluído na rotina organizacional e que exige uma análise dos esforços desprendidos até o momento para que haja sempre uma maior efetividade em sua execução.

A partir de uma investigação científica acerca da experiência do IFSC, este artigo apresenta como objetivo geral uma proposta de ações de melhoria para o processo de construção de políticas de comunicação em instituições de educação profissional, científica e tecnológica. Para atingir o objetivo geral, foram desenvolvidos os seguintes objetivos específicos: (a) descrever o processo de construção da Política de Comunicação do IFSC; (b) analisar os fatores restritivos e facilitadores do processo utilizado na construção da Política de Comunicação do IFSC; e (c) avaliar o processo 
utilizado na construção da Política de Comunicação do IFSC perante as abordagens de aprendizagem organizacional e mudança estratégica, e dos estudos de comunicação organizacional. Com base nesses objetivos, tornou-se possível propor ações de melhoria no processo de construção de uma política de comunicação para instituições de educação profissional, científica e tecnológica, além de apresentar sugestões para o processo de atualização do documento para o IFSC.

\section{FUNDAMENTAÇÃO TEÓRICA}

O termo comunicação passou a ser mais fortemente considerado na administração em fins da década de 1940 e início da de 1950, quando as organizações tornaram-se mais conscientes das pessoas, e os cientistas do comportamento começaram a aplicar suas pesquisas nas organizações (MEGGINSON; MOSLEY; PIETRI, 1986). Assim, a partir da década de 70, já é possível notar mais claramente a importância estratégica da comunicação para as organizações (TORQUATO, 2010). Dentro dessa perspectiva, Simon (1979) é um dos autores que afirma que não pode haver organização sem comunicação, uma vez que não existiria a possibilidade de o grupo influenciar o comportamento do indivíduo.

De acordo com Goodman e Hirsch (2010), o papel da comunicação mudou nas organizações, assim como a natureza das organizações modificou-se em resposta a uma explosão de novas tecnologias de comunicação. "A comunicação é mais complexa, estratégica e vital para a saúde da organização do que era antes, e só vai ganhar importância na economia baseada na informação" (GOODMAN; HIRSCH, 2010, p. 17, tradução nossa).

Quando a comunicação é abordada no contexto de uma organização, denomina-se comunicação empresarial, institucional, corporativa ou organizacional. As nomenclaturas variam de acordo com os autores (BUENO, 2009; KUNSCH, 2003; PIMENTA, 2002; RABAÇA; BARBOSA; SODRE, 1987), mas levam ao mesmo entendimento. De maneira geral, entende-se comunicação empresarial ou comunicação organizacional como o "conjunto integrado de ações, estratégias, planos, políticas e produtos planejados e desenvolvidos por uma organização para estabelecer a relação permanente e sistemática com todos os seus públicos de interesse" (BUENO, 2009, p. 3-4).

Atualmente, espera-se que a comunicação assuma um novo papel, deixando de ser responsabilidade de um único setor e tornando-se uma função de toda a instituição, incorporandose à sua gestão estratégica. Conforme Cardoso (2006, p. 1134), ela deve "servir de suporte para um modelo de gestão bem estruturado e com capacidade de levar a empresa a enfrentar os desafios cada vez mais competitivos de uma sociedade que se torna mais exigente em qualidade e em direitos".

Se por um lado a perspectiva sobre o valor dado à comunicação nas instituições parece mais otimista diante de pesquisas que demonstram essa conquista de espaço, ainda há uma lacuna a ser superada. É raro encontrar instituições que tenham elaborado e implantado uma política de comunicação efetiva, reconhecida interna e externamente, e com resultados perceptíveis. Nassar (2005) afirma que são poucas as organizações que pensam sobre os conceitos política de comunicação, plano de comunicação e ações de comunicação. Whitney $(1989$, p. 85, tradução nossa) afirma que, "apesar de as políticas de comunicação terem se revelado úteis e importantes, elas não são universalmente encontradas nem universalmente valorizadas nas empresas". A autora argumenta que a informação era um importante bem da empresa e a forma como ela era transmitida poderia ajudar ou atrapalhar no atingimento das metas da organização. Daí a importância de se ter uma política de comunicação. "Se nós enxergarmos as interações dos indivíduos dentro de uma organização como crucial, então podemos entender a política de comunicação como uma força orientadora na empresa como um todo" (WHITNEY, 1989, p. 76, tradução nossa).

Bueno $(2009$, p. 38) salienta que a comunicação com inteligência inicia-se com um planejamento adequado, o que quer dizer que "o planejamento em comunicação deve resultar de uma política de comunicação, instrumento de gestão que vislumbra ações e estratégias também de longo prazo". De acordo com Kunsch (2003, p. 273), "definir uma política global de comunicação é algo fundamental, pois é ela que deverá direcionar toda a comunicação da empresa ou da organização".

Ao construir sua política de comunicação na busca de uma mudança estratégica, pode-se dizer que uma organização passa por uma aprendizagem organizacional, concebida como o principal meio de alcançar a renovação estratégica de uma organização (CROSSAN; LANE; WHITE, 1999). Essa renovação exige que as organizações explorem e aprendam novas formas de atuar e, para ser estratégica, deve abranger toda a organização - e não apenas o indivíduo ou grupo -, reconhecendo ainda que a organização opera em um sistema aberto, em vez de ter um foco apenas interno (CROSSAN; LANE; WHITE, 1999).

Na abordagem de Argyris e Schön (1996), o modelo de aprendizagem organizacional inclui 
o produto (conteúdo informacional), o processo (aquisição, processamento e armazenamento da informação) e o aprendiz (a quem o processo de aprendizagem é atribuído). De acordo com os autores, as organizações aprendem quando adquirem informação de qualquer tipo ou significado, transformando-a em conhecimento e práticas.

Pode-se compreender o processo de construção da política como uma aprendizagem organizacional com base no quadro de aprendizagem apresentado por Crossan, Lane e White (1999), formado por quatro premissas: (1) a aprendizagem organizacional envolve uma tensão entre assimilar novas aprendizagens e usar o que já foi aprendido; (2) a aprendizagem organizacional é multinível: individual, grupal e organizacional; (3) os três níveis de aprendizagem organizacional estão ligados por processos sociais e psicológicos: intuição, interpretação, integração e institucionalização; e (4) a cognição afeta a ação (e vice-versa).

Ao longo do processo, instituições empenhadas em mudanças organizacionais podem se deparar com a resistência das pessoas ao novo. "Parte dessa resistência decorre da experiência do aprendizado como perda, e não como adição de um outro 'saber'" (AMORIM, 1999, p. 101). O aprendizado institucional é ainda mais difícil que o individual, uma vez que depende de uma ampla mudança nos diversos grupos da organização - tanto na compreensão das novas diretrizes como na sua internalização e aplicação prática.

A necessidade de mudança diante de um ambiente cada vez mais dinâmico atinge a todas as organizações. Essa inevitabilidade em mudar pode fazer com que uma instituição sinta-se obrigada a isso ou pode partir dela essa iniciativa. A construção de uma política de comunicação pode representar uma mudança estratégica para a organização, a partir do momento em que pressupõe uma quebra de paradigma na forma de enxergar a comunicação, envolvendo inclusive uma mudança cultural.

Uma mudança estratégica deve ser vista como um processo humano complexo em que todos desempenham sua parte (PETTIGREW, 1996). Conforme afirma o autor, "a formulação do conteúdo de qualquer nova estratégia acarreta inevitavelmente a gestão de seu contexto e processo" (PETTIGREW, 1987, p. 657, tradução nossa). Dessa forma, Pettigrew (1987) propõe um amplo quadro que orienta pesquisas nesse sentido, em que a mudança pode ser analisada por três pontos: o que mudou (conteúdo), por que mudou (contexto interno e externo) e como mudou (análise do processo). Ainda segundo o autor, o ponto de partida para analisar uma mudança estratégica é "a noção de que a formulação do conteúdo de qualquer nova estratégia, inevitavelmente, supõe controlar seu contexto e processo" (PETTIGREW, 1996, p. 147).

O modelo clássico de mudança organizacional baseia-se na proposta de Lewin (1951 apud LIMA; BRESSAN, 2003) para a mudança social, envolvendo um processo que abarca três atividades: descongelamento, mudança ou movimento e recongelamento. Para que uma mudança obtenha sucesso, ela só pode acontecer quando os colaboradores da organização estão dispostos a devotar tempo e energia necessários para atingir novas metas. Grouard e Meston (2001) igualmente ressaltam que a participação é o ponto de partida para a criação de uma dinâmica para o envolvimento, apoio e sucesso dos colaboradores no processo de mudança.

Segundo Dutra (1996), não é possível descolar o processo de mudança da cultura organizacional existente, porque há uma profunda influência desta sobre o processo. A única maneira efetiva de modificar uma organização é por meio de sua cultura (MARCHIORI, 2008). No caso das organizações que ainda não encaram a comunicação como área estratégica à gestão, é preciso mudar essa postura com base na cultura organizacional. E esse não é um processo fácil. "A cultura é difícil de ser mudada, porque os membros do grupo valorizam a estabilidade no que ela fornece significado e previsibilidade" (SCHEIN, 2009, p. 13).

Conforme Bueno (2009, p. 21), "uma organização necessita mais do que apenas profissionais de comunicação competentes ou caixinhas no organograma. Ela precisa construir uma cultura de comunicação". A cultura de comunicação "pressupõe a oxigenação dos canais de relacionamento e a valorização dos saberes, das competências e experiências de todas as pessoas" (BUENO, 2009, p. 2324). Acredita-se que isso é possível com a construção coletiva de uma política de comunicação que gere uma discussão institucional a respeito do tema e leve a uma reflexão e a um comprometimento por parte dos funcionários de que a comunicação é responsabilidade de todos.

\section{METODOLOGIA}

Este artigo é resultado de um estudo de caso (BRUYNE; HERMAN; SCHOUTHEETE, 1991; YIN, 2005) do processo de construção da Política de Comunicação do IFSC. Como técnicas de coletas de dados, foram utilizadas análise documental, observação (MALHOTRA, 2006; MCDANIEL; GATES, 2006; PÁDUA, 2008), observação participante, entrevistas (FLICK, 2004) e levantamento (GIL, 1999). A 
pesquisa dividiu-se em duas etapas: uma qualitativa e outra quantitativa.

Para que se tivesse uma perspectiva mais ampla do processo de construção da política de comunicação do IFSC, que não se restringisse à observação das pesquisadoras, optou-se por se entrevistar dez integrantes da comissão responsável por esse projeto, além de dois gestores que pudessem esclarecer o envolvimento e o papel da gestão no processo, e igualmente o consultor que auxiliou o trabalho. Buscando ampliar a perspectiva da pesquisa, julgou-se adequado compreender a percepção do processo de construção da política de comunicação pelos servidores do IFSC e não só daqueles envolvidos diretamente no projeto. Para essa etapa, foram aplicados questionários on-line disponibilizados para todos os servidores da instituição. Trabalhando com um universo de 2.016 servidores e uma amostra de 641 elementos, o erro estimado para esta pesquisa ficou em $3,26 \%$. Utilizou-se um questionário estruturado com treze questões abertas e fechadas, sendo doze obrigatórias e a última com um comentário optativo. O questionário abordou o processo de construção da política de comunicação do IFSC, com destaque para os fatores facilitadores e restritivos ao processo identificados pelos respondentes. O questionário foi desenvolvido por meio do software livre utilizado na instituição para pesquisas on-line, o Lime Survey, e enviado pela internet para os servidores. A opção por aplicar o questionário de maneira on-line permitiu que fossem atingidos todos os servidores do IFSC, uma vez que se trata de uma instituição multicampi e espalhada geograficamente.

Como o objetivo desta pesquisa foi verificar a percepção dos servidores do IFSC relativamente ao processo de construção da política de comunicação institucional, o universo do trabalho ficou delimitado a todos os servidores, em virtude da importância em se obter o maior número possível de respostas ao instrumento de coleta. Por esse motivo, optou-se pela remessa a todos os elementos do universo, na expectativa de se conseguir dados mais significativos que, envolvendo menor erro amostral, permitissem generalizar o resultado obtido.

\section{A CONSTRUÇÃO DA POLÍTICA DE COMUNICAÇÃO DO IFSC}

O IFSC surgiu como Escola de Aprendizes Artífices de Santa Catarina, instalada em 1910 em Florianópolis. Ao longo da história, o nome e a atuação da organização mudaram diversas vezes até a transformação em Instituto Federal, em 2008, com a criação da Rede Federal de EPCT. Como uma autarquia federal, vinculada ao MEC, o IFSC possui autonomia administrativa, patrimonial, financeira, didático-pedagógica e disciplinar. Atualmente, a instituição conta com dezenove campi em funcionamento, dois em implantação e um campus avançado. Com toda a sua estrutura, a instituição atende a cerca de vinte mil alunos em cursos presenciais e mais três mil aproximadamente em cursos a distância. Para permitir esse funcionamento, cerca de dois mil servidores concursados - incluindo docentes e técnicos administrativos - trabalham em todos os campi e na Reitoria.

A expansão do IFSC - ainda como CEFET-SC -, a partir de 2006, potencializou os problemas enfrentados pela instituição diante da falta de uma estrutura de comunicação profissionalizada. Apesar de ser uma organização centenária, as mudanças de nome fizeram com que a marca se enfraquecesse e muitos não associassem a nova institucionalidade à reputação já adquirida. Com isso, havia uma fragmentação da imagem, uma vez que cada unidade fazia suas ações sem haver um alinhamento na divulgação.

Mais do que não ter uma estrutura de comunicação formalizada e com profissionais com formação técnica, a instituição nunca se havia preocupado em definir diretrizes para essa atividade. Com a entrada de profissionais concursados com formação em comunicação para cargos específicos para o setor - como jornalistas e programadores visuais - e com a criação da Diretoria de Comunicação (Dircom) em 2009, essa necessidade de haver uma orientação para procedimentos de comunicação ficou mais evidente.

Apesar de já haver a percepção com a necessidade de se ter uma política de comunicação, apenas em 2011 é que começou efetivamente um movimento para que a ideia saísse do papel. Num primeiro momento, tentou-se fazer um projeto interno - que acabou não indo adiante em razão das inúmeras demandas e rotina diária da equipe de comunicação. Só em 2012 o projeto tomou corpo, com o apoio da gestão do Instituto para a contratação de um consultor externo a fim de auxiliar no processo. Apesar do custo com a consultoria, o papel de um consultor foi considerado fundamental pela equipe, em virtude de sua experiência, sua visão externa - não comprometida com certos vícios, rotinas e hierarquias - e para ajudar na sensibilização dos servidores a propósito da importância de se construir uma política de comunicação.

Além do apoio da Alta Administração, outro fato também foi fundamental para que o projeto de construção da política de comunicação fosse institucionalizado. Durante o Seminário de 
Planejamento 2013-2014, realizado para definir o planejamento do IFSC dos dois anos seguintes, a comunicação ganhou um espaço de destaque. Dos dezoito macroprojetos institucionais definidos no evento, realizado em 2012, ficou estabelecido que o macroprojeto 15 seria a Política de Comunicação Institucional.

\subsection{O processo}

A construção da política de comunicação do IFSC envolveu sete reuniões entre o consultor e a comissão de construção da política - grupo designado por meio de Portaria e formado pelos servidores da Dircom, além de uma representação dos campi, sendo a Diretora de Comunicação nomeada como Presidente da Comissão. As reuniões duravam um dia inteiro. Os temas das reuniões eram propostos pelo consultor, mas havia sempre um alinhamento com a Presidente da Comissão que solicitava ou não a inclusão de mais pontos para a discussão. De acordo com o tema a ser discutido, outros servidores eram convidados a participar dos encontros.

As reuniões funcionaram todas, basicamente, da mesma forma: o consultor fazia uma explanação acerca do tema, com conhecimento prévio da realidade do IFSC (uma vez que já tinha estudado a instituição por meio de diversos documentos enviados pela coordenadora do projeto) e expunha ao grupo suas sugestões para organizar determinado ponto. Os integrantes da comissão discutiam a questão entre si com o auxílio do consultor e já escreviam em conjunto a proposta de encaminhamento para cada tema com base no texto trazido pelo consultor. O consultor, por sua vez, consolidava posteriormente as sugestões da comissão e encaminhava o texto por e-mail novamente para apreciação do grupo. Além da construção dos textos durante as reuniões, todos os textos foram revistos pelos integrantes da comissão ao final dos encontros até formarem a proposta de política de comunicação que foi posta para apreciação de todos os servidores como minuta.

Para facilitar a comunicação, foi criado um grupo de e-mail entre os integrantes da comissão e o consultor para troca de informações. O grupo on-line permitia que a discussão também fosse ampliada a um espaço virtual, não ficando restrita apenas aos encontros presenciais.

Além das reuniões com o consultor, sempre que se julgou necessário, a comissão reuniu-se no período entre essas ocasiões para encaminhar pendências que não eram sanadas por completo nas reuniões em que havia a presença do consultor ou que exigiam uma discussão maior. Nesses encontros, nem sempre todos os integrantes da comissão participavam. A Presidente da Comissão marcava a reunião e abria a participação para que todos pudessem comparecer. Posteriormente, as decisões eram compartilhadas com todos da comissão pelo grupo de e-mail ou nas reuniões com a presença do consultor.

A partir da primeira reunião de apresentação do trabalho com o consultor e do estabelecimento do cronograma para o desenvolvimento do projeto, o compartilhamento de tudo o que seria feito foi uma preocupação da comissão responsável por construir a política de comunicação do IFSC. Entendiase que era preciso sensibilizar os servidores de maneira geral para que eles compreendessem o que estava para acontecer e se envolvessem de fato no processo. Essa sensibilização foi feita por meio de ações de comunicação, como envio de e-mails, divulgação de notícias nos canais de comunicação institucionais e eventos.

Para facilitar a divulgação do processo, concentrando todas as informações em um só lugar, a comissão responsável pelo projeto decidiu criar um ambiente virtual exclusivo para a política de comunicação do IFSC. No site www.politicadecomunicacao.ifsc.edu.br, foram postadas, ao longo da construção do documento, notícias após cada reunião de trabalho. Era nesse ambiente também que os públicos eram convidados a participar das pesquisas e podiam enviar sugestões e dúvidas. Esse site era destinado a todos os públicos envolvidos e continua ativo, compartilhando informações acerca do processo de implementação da política e disponível para receber sugestões para sua atualização.

Para além desse canal, os servidores do IFSC tinham acesso a um Fórum exclusivo on-line em que eram compartilhados documentos, apresentações de cada reunião e resultados de pesquisas. Foi nesse espaço com acesso restrito que foi disponibilizada a minuta da política para apreciação dos servidores. Por funcionar num sistema de fórum, o canal permitia também a troca de ideias entre eles.

Os demais canais de comunicação do IFSC igualmente foram utilizados para divulgar as etapas do processo. Foram feitos ainda cartazes e banners sobre a política de comunicação, que foram espalhados pela Reitoria e enviados a todos os campi para que fosse feita uma ampla divulgação.

A fim de que os servidores pudessem envolver-se desde o início no processo de construção da política de comunicação e para representar a importância do momento para todo o Instituto, a comissão decidiu promover um evento em Florianópolis - no início de 2013 - com o intuito de 
lançar o processo. Chamado de seminário de lançamento do processo de construção da Política de Comunicação do IFSC, o evento contou com a presença de cerca de cem servidores, representando todos os campi e setores da Reitoria.

\subsection{Construção coletiva}

Uma das premissas de uma política de comunicação é que ela precisa ser concebida com a participação efetiva dos públicos internos. A preocupação de que sempre houvesse a participação dos públicos, especialmente os servidores, foi uma constante em todo o processo do IFSC, presente nos discursos e nas ações. Dessa forma, essa construção coletiva fez com que a política do Instituto fosse resultado da participação livre e espontânea dos públicos, estimulados a todo o instante pela comissão a se engajarem no propósito.

Com o intuito de permitir a participação de todos, mesmo em eventos em que, por limitação de espaço físico e de liberação de diárias e passagens para os servidores não era possível trazer tantos participantes presenciais, buscou-se fazer a transmissão on-line. Isso foi feito tanto no lançamento do processo quanto no lançamento do documento.

Durante todo o processo, qualquer pessoa podia acompanhar as etapas pelo ambiente virtual da política e enviar dúvidas e sugestões pelo formulário de contato disponível no site disponibilizado ou pelo e-mail da Dircom. Para os servidores, foi criado ainda um tópico dentro de uma ferramenta on-line de Fórum do IFSC em que era possível deixar considerações a respeito do processo. Essas sugestões eram, inclusive, estimuladas pela comissão que criava tópicos específicos para isso.

Com o objetivo de incentivar ainda mais a participação de todos - de maneira mais estruturada -, foram realizadas sondagens em períodos específicos em que os públicos foram convidados a responder pesquisas a propósito da comunicação do IFSC. A intenção foi fazer com que o assunto permanecesse vivo na pauta da instituição.

Após passar por apreciação e aprovação de todos os servidores e das instâncias normativas da instituição - Colégio de Dirigentes e Conselho Superior -, a política de comunicação do IFSC foi lançada em uma solenidade, em setembro de 2013. A partir da definição dos públicos, foram propostos princípios, posturas e normas com o objetivo de orientar a interação com esses públicos. Assim, a política de comunicação definida pelo IFSC foi documentada em quinze capítulos, divididos por temas relevantes ao processo sistêmico de comunicação do Instituto, organizados da seguinte forma: (1) Comunicação Organizacional: conceitos e tendências. (2) Comunicação no ambiente organizacional. (3) Definição dos públicos estratégicos do IFSC. (4) Comunicação Interna do IFSC. (5) Canais de relacionamento do IFSC. (6) Relacionamento com a imprensa. (7) Fontes do IFSC. (8) Planejamento, realização, promoção, apoio e patrocínio de eventos. (9) Comunicação e divulgação científicas do IFSC. (10) Campanhas de Ingresso. (11) O IFSC nas mídias sociais. (12) Comunicação e gestão de crises. (13) Gestão da comunicação do IFSC. (14) Plano de Comunicação do IFSC. (15) Divulgação e internalização da Política de Comunicação.

\subsection{Recomendações}

Com base nas pesquisas bibliográfica, qualitativa e quantitativa realizadas, propõem-se sugestões para a construção e atualização de políticas de comunicação, tendo como base a experiência do IFSC. Às instituições que queiram empreender uma iniciativa como essa, sugerem-se as recomendações que seguem, as quais são complementadas pelo Quadro 1 na sequência.

O entendimento de que a definição de uma política deve partir da Alta Administração é ponto comum de diversos autores (STEINER;MINER, 1981;BUENO, 2009).Tais autores destacam que o caminho do sucesso pressupõe que os gestores do mais alto escalão devam estar envolvidos no processo. Mas, para além dos chefes, toda a empresa precisa ser envolvida - e isso ultrapassa a divulgação da construção para todos. É preciso buscar maneiras de sensibilizar de fato os colaboradores a fim de que se envolvam e participem efetivamente, dando contribuições e entendendo que a definição de diretrizes facilitará o seu trabalho e melhorará a comunicação da organização. Nesse sentido, a construção coletiva é fundamental para legitimar o processo.

Alguns autores reforçam essa necessidade de envolver outras áreas. Conforme Penteado (1978, p. 141), "traçar as directrizes dessa política, naquilo em que ela se aplica para cada um dos públicos da empresa, é tarefa conjunta da Administração Superior e do profissional de Relações Públicas". Steiner e Miner (1981) lembram que a implantação de políticas está ligada ao projeto e à administração de sistemas para se conseguir a melhor integração das pessoas, estruturas, processos e recursos com a finalidade de se atingir os objetivos organizacionais.

Além do engajamento dos dirigentes, é preciso identificar um líder para coordenar o projeto 
de mudança. "A liderança deve proteger o projeto, reunir os recursos necessários e assumir a responsabilidade por seu sucesso ou fracasso" (BEER, 2010, p. 52). Com base na experiência do IFSC, recomenda-se que esse líder seja alguém da própria organização, com perfil para motivar a equipe e executar o projeto, além de possuir certa influência política relativamente aos gestores da organização. Além dessa pessoa, outro papel indicado para se definir - em prol da condução do processo - é o de um coordenador mais operacional para auxiliar o líder na gestão do projeto, cobrando atividades, estabelecendo prazos, divulgando as ações e organizando a interação com o público.

Analisando o processo do IFSC, uma melhoria recomendada por alguns integrantes é que se fizesse um grupo com mais representatividade dos campi, com a ressalva de que tais representantes fossem servidores, preferencialmente, com formação em comunicação e também com disponibilidade e vontade de contribuir. Outro cuidado que precisa ser tomado é o de não incluir no grupo as pessoas pela simples razão de fazerem parte do setor, mas sim porque elas querem e irão de fato participar e envolver-se no processo. Nesse sentido, a realização de uma reunião com o grupo da Dircom, cobrando esse comprometimento como condição para participar da comissão e, ao mesmo tempo, mostrando a necessidade de todos de fato participarem, seria muito importante.

O comprometimento é uma dificuldade a ser vencida tanto no que concerne aos gestores, e aos profissionais da área, como aos colaboradores de maneira geral, o que foi uma das fragilidades do processo do IFSC. A sensibilização, portanto, é um dos grandes desafios no processo. Torna-se importante pensar maneiras de mostrar para as pessoas como elas são responsáveis pela comunicação da instituição na qual trabalham, em como o seu trabalho afeta, direta e indiretamente, cada público estratégico, e como a política irá ajudá-las a aprimorar o seu fazer diário e, consequentemente, qualificar a comunicação de sua organização.

A partir do momento em que se decidir pela política, deve ficar claro que ela servirá não apenas para a comunicação, mas permeará todos os setores da organização. Uma política de comunicação parte do pressuposto de que todas as pessoas da organização são responsáveis pela comunicação.

No caso do IFSC, a estratégia utilizada para buscar o engajamento dos servidores foram os materiais gráficos - como cartazes impressos, banners impressos e eletrônicos, além de artes para as mídias sociais. Apesar da realização de todas essas ações, elas não foram suficientes para mobilizar os servidores do IFSC do modo como se esperava, o que não quer dizer que não são indicadas, pelo contrário. Qualquer organização que esteja iniciando um processo de construção de uma política precisa estar atenta para planejar as formas de sensibilização possíveis - o que envolve a elaboração de materiais gráficos, podendo ir ainda mais além.

Passada a dificuldade de convencer a todos da importância de se ter uma política, o próximo passo será demonstrar que o processo de criação é complexo. A metodologia pode ser trazida por um consultor com experiência ou definida internamente.

No caso do IFSC, como exposto, o consultor apresentou sua metodologia, mas esta sofreu adaptações conforme a equipe interna julgou necessário para o andamento e o enriquecimento do processo.

Independentemente da metodologia a ser seguida, uma etapa é imprescindível a qualquer processo dessa natureza: antes de discutir qualquer temática relacionada à comunicação, a organização tem de ter claro quem são os públicos da instituição. Mesmo que a organização já tenha essa definição, esse será um bom momento para refletir sobre isso e verificar se os públicos já definidos estão de acordo com a missão e a visão da instituição, se devem ser ampliados ou até mesmo reduzidos.

Por mais que seja difícil envolver as pessoas no processo e que a busca por essa participação torne tal processo mais complexo e demorado, é extremamente recomendado que haja esse caráter de construção coletiva - principalmente se envolver instituições públicas.

Uma sugestão proposta pelos servidores do IFSC para tornar o processo mais próximo dos campi e talvez, com isso, angariar maiores contribuições foi a criação de comissões locais em cada campus, com servidores com competência na área e que pudessem facilitar o engajamento in loco. No caso do IFSC, na pesquisa quantitativa, alguns servidores sugeriram que houvesse um tempo maior de discussão. Esse é outro parâmetro que dependerá de cada instituição. Um tempo maior não significará necessariamente uma maior participação. Por outro lado, a rapidez do processo não pode limitar a reflexão aprofundada e tampouco a abertura para participação, ao mesmo tempo em que o prazo deve ser cumprido e encaminhamentos devem ser dados. Por isso, a questão do tempo é relativa. Mais importante do que a duração do processo é pensar formas de torná-lo eficiente.

Uma recomendação que parece óbvia, mas é importante ser registrada - conforme apontada por alguns autores (PÉNTEADO, 1978; BUENO, 2009) e também por um dos integrantes da comissão durante a entrevista para este trabalho é que, se a organização não tiver condições posteriores ou vontade para implementar o documento, não deve nem iniciar o processo. 
Com base nos dados da pesquisa, no Quadro 1 são resumidas as sugestões para a construção e atualização de políticas de comunicação em instituições de educação profissional, científica e tecnológica.

Quadro 1 - Recomendações para a construção de uma política de comunicação

1. Identifique um líder interno com perfil para motivar a equipe e executar o projeto, além de possuir certa influência política no que diz respeito aos gestores da organização.

2. Escolha um coordenador mais operacional para auxiliar o líder na gestão do projeto, cobrando atividades, estabelecendo prazos, divulgando as ações e organizando a interação com os públicos.

3. Se possível, contrate um consultor externo com experiência no assunto, que traga uma visão isenta para o processo, dê respaldo perante o público interno e auxilie as discussões.

4. Designe um grupo de pessoas da área de comunicação para comandar o processo e oficialize por meio de portaria para dar mais força de comando.

5. Invista fortemente na sensibilização de toda a comunidade, principalmente o público interno, antes de iniciar os trabalhos e durante todo o processo.

6. Busque um envolvimento ainda maior dos gestores da instituição para que eles não só sejam participantes, mas patrocinadores, mobilizadores e incentivadores do processo.

7. Tenha claro quem são os públicos da instituição.

8. Crie canais de comunicação específicos para divulgar o processo e interagir com os públicos, além de utilizar os que a instituição já possui.

9. Tenha um diagnóstico da comunicação, por meio de uma pesquisa ou levantamento, antes de iniciar o processo.

10. Inclua representantes das unidades e setores na discussão.

11. Para legitimar o processo, desenvolva o trabalho com um caráter de construção coletiva, dando às pessoas a oportunidade de contribuírem com o documento. fóruns.

12. Use as tecnologias disponíveis para promover a participação, como formulários on-line e

13. Promova eventos para enaltecer o processo - principalmente no início e no fim -, engajar mais as pessoas e permitir a troca de ideias de forma presencial.

14. Busque alinhar a agenda institucional para que a política seja construída em um período em que não haja outros processos paralelos que possam "competir" pela atenção dos colaboradores.

15. Não deixe que disputas políticas atrapalhem o processo, uma vez que a política não é feita por e para uma gestão, mas sim para a instituição e, portanto, deve perdurar independentemente de quem estiver no comando.

16. O conteúdo deve ser o mais amplo possível, por mais que reflita as peculiaridades da organização, com diretrizes mais estratégicas e não apenas questões pontuais de teor mais operacional.

17. Não tenha receio dos conflitos. As resistências existirão e são importantes para que a instituição reflita e faça da discussão um momento de aprendizado organizacional.

Fonte: Elaborado pelas autoras (2014)

Além de pensar na elaboração da política, é imprescindível preocupar-se com a implantação do processo. Uma ação que faz parte da implementação e acaba sendo uma constante, a partir do lançamento do documento, é a sua atualização. Afinal, conforme aponta Bueno (2014), a política de comunicação tem de ser aplicada, monitorada, rediscutida constantemente, uma vez que a inserção das organizações na sociedade obedece a um processo dinâmico e não se congela no tempo.

Com base nas sugestões dos servidores e da percepção das pesquisadoras, recomenda-se que o processo de atualização de uma política de comunicação inclua as seguintes premissas (Quadro 2). 
Quadro 2 - Recomendações para a atualização de uma política de comunicação

1. Crie uma comissão representativa para monitorar o documento e oriente seus integrantes sobre o papel de cada um.

2. Estabeleça critérios que permitam à comissão acompanhar a internalização da política.

3. Promova reuniões presenciais periódicas com os integrantes da comissão para que haja o comprometimento e o espírito de equipe necessários a fim de que o grupo execute sua função da melhor maneira possível.

4. Deixe espaços permanentes abertos à comunidade para o envio de sugestões.

5. Continue sensibilizando constantemente o público interno - com atenção especial aos gestores - para que todos conheçam o documento, por meio de palestras, capacitações, produção de peças gráficas, divulgação de notícias sobre o tema e outras formas de interação que possam ser desenvolvidas.

6. Determine a periodicidade para a atualização de modo que não seja tão curto o tempo que não permita o amadurecimento das diretrizes, nem tão longo a ponto de se tornar ultrapassado e inútil para a organização.

7. Avalie a necessidade de se contratar um consultor para auxiliar o processo com base no nível de atualização pretendido.

8. Defina indicadores para permitir avaliar o que foi efetivo nas diretrizes a fim de que possa ser aprimorado, alterado ou até excluído da proposta.

9. Quando a hora de iniciar o processo estiver se aproximando, planeje um cronograma de trabalho para a comissão, prevendo encontros presenciais e ações a serem feitas em cada local de trabalho. É importante que não haja muitas discussões institucionais em paralelo nesse momento para que o foco seja realmente a política de comunicação.

Fonte: Elaborado pelas autoras (2014)

É necessário ter claro que, por maior envolvimento e participação que se tenha na construção do documento, ele não será imutável. A atualização deve fazer parte do processo e será uma constante a ser incorporada na rotina de trabalho da instituição. Afinal, de nada valerá existirem diretrizes que não acompanhem o desenvolvimento dos contextos interno e externo e que, por isso, acabem sendo destinadas a não saírem do papel.

\section{CONCLUSÃO}

Construir uma política de comunicação foi o caminho encontrado pelo IFSC para assumir a comunicação como estratégica para a organização. A opção por realizar uma construção coletiva foi feita para legitimar o processo de maneira que, a partir da construção e implementação da política, a comunicação seja entendida e assumida como um compromisso de todos os servidores a fim de que o Instituto possa realizar sua função social de maneira mais eficiente e atingir seus objetivos organizacionais.

Entre os fatores facilitadores do processo, identificaram-se a criação de um ambiente virtual específico para a sua divulgação; o apoio da Gestão e a existência de uma vontade política para realizar o trabalho; a contratação de um consultor externo com a finalidade de ajudar no desenvolvimento do projeto; a existência de uma liderança interna com perfil adequado para o projeto; a proximidade física dos integrantes da comissão; o conhecimento técnico e prático da comissão; o pioneirismo da iniciativa; o uso de tecnologias (formulários on-line); e a metodologia utilizada com caráter democrático e participativo.

Já, entre os fatores restritivos ao processo, ou seja, aqueles que dificultaram seu andamento, citam-se o grande volume de trabalho no dia a dia dos servidores; a ocorrência de diversos processos institucionais acontecendo ao mesmo tempo; a falta de envolvimento de gestores na Reitoria e nos campi - e dos servidores de maneira geral; a estrutura da instituição pelo seu tamanho e abrangência; a falta de entendimento dos servidores sobre a política em si; e a visão restrita da comunicação já pré-concebida.

Com base em estudos da área (ARGYRIS; SCHÖN, 1978; CROSSAN; LANE; WHITE, 1999; HUBER, 1991; NONAKA; TAKEUCHI, 1997; SHRIVASTAVA, 1983), percebeu-se que a construção da política de comunicação do IFSC pode ser considerada um processo de aprendizagem organizacional. Pela abordagem de Argyris e Schön (1996), pode ser caracterizada, inclusive, como uma aprendizagem organizacional de ciclo duplo, uma vez que envolveu mudanças nas regras e procedimentos que sustentam as ações e os comportamentos da organização. Além disso, o processo do IFSC pode ser 
percebido a partir da evolução dos níveis (individual, grupal e organizacional) e dos processos sociais e psicológicos apontados por Crossan, Lane e White (1999) de intuição, interpretação, integração e institucionalização. Para chegar ao estágio de institucionalização, a organização ainda levará mais tempo, mas só pela aprendizagem individual e grupal já observada até o momento, acredita-se que isso efetivamente ocorrerá.

Ao entender a construção da Política de Comunicação do IFSC com base nas dimensões de mudança de Pettigrew (1987), constata-se uma tendência do processo de desencadear uma mudança estratégica na instituição, a partir da criação de uma cultura de comunicação atrelada à cultura organizacional. Resgatando o modelo clássico de mudança organizacional (LEWIN, 1951 apud LIMA; BRESSAN, 2003), pode-se dizer que o IFSC já passou pela primeira fase do descongelamento e, agora, vivencia a mudança ou movimento. A última etapa - do recongelamento, com a institucionalização de novas estruturas e padrões de comportamento - só poderá ser percebida daqui a alguns anos. Afinal, todo processo de mudança tem o seu período de maturação e é preciso aguardar os resultados que dele virão.

Com a constatação da comunicação como um processo relacionado a vários outros processos organizacionais, entende-se que ela não pode mais ser amadora nem desestruturada, pois que é responsável pela sustentabilidade institucional. Um planejamento adequado de comunicação deve partir de uma política de comunicação bem sistematizada e bem construída. Só com uma política dessa natureza é que a organização conseguirá construir uma cultura de comunicação, alicerçada no exercício das competências individuais tendo em vista o interesse coletivo. É por meio dessa política que a organização explicitará posturas e estratégias que balizarão o relacionamento com os seus públicos de interesse. A deflagração do processo de sua construção por si só já propiciará um saudável debate interno sobre as competências em comunicação e promoverá a mobilização e a capacitação para superar os desafios. Enfim, com a Política de Comunicação, a organização compromete-se com uma visão moderna de comunicação organizacional que concilia objetivos, visão e missão da instituição com as demandas e expectativas do mercado e da sociedade; e promove a articulação entre a filosofia de gestão e a cultura organizacional tendo em vista a obtenção de resultados em comunicação.

No caso do IFSC, a Política de Comunicação fortaleceu e deu base para uma qualificação permanente da comunicação. Mais do que isso, ela institucionalizou a visão de comunicação como estratégica para a organização, ainda que não seja a sua área-fim. Com o documento, também ganha força a contratação de profissionais por meio de concurso público para a área e a estruturação dos setores nos campi, o que é fundamental para que se possa fazer um trabalho de qualidade.

A pesquisa aqui realizada suscita a necessidade de novos estudos a respeito da construção de políticas de comunicação em instituições de ensino. Recomenda-se que novas investigações sejam realizadas em instituições de ensino de outra natureza, como as universidades públicas e as privadas, assim como novas investigações no próprio IFSC de forma a avaliar a evolução do processo estudado.

\title{
COMMUNICATION POLICY IN INSTITUTIONS FOR PROFESSIONAL, SCIENTIFIC AND TECHNOLOGICAL EDUCATION: PROPOSAL FROM IFSC'S EXPERIENCE
}

\begin{abstract}
The present article is about the establishment of a Policy of Communication in the Federal Institute of Santa Catarina (IFSC). The IFSC's experience is described as an organizational learning that leads to a strategic change. Qualitative and quantitative researches were performed aiming to propose improving actions in the process of establishing and updating of communication policies in institutions for professional, scientific and technological education. It was concluded that it is necessary that such a process must be a collective construction, with the support of senior management. That is the only way that will allow the communication to be understood as a commitment by all collaborators and to be incorporated as strategic organizational routine.
\end{abstract}

Keywords: Policy of communication. Organizational Communication. Organizational learning. Strategic change. 


\section{REFERÊNCIAS}

AMORIM, Maria Cristina Sanches. Comunicação planejada, recurso fundamental para a eficácia da gestão organizacional. Caderno de Pesquisas em Administração, São Paulo, v. 1, n. 9, p. 98-109, 1999.

ARGYRIS, Chris; SCHÖN, Donald A. Organizational Learning: a Theory of Action Perspective. Reading: Addison-Wesley, 1978.

ARGYRIS, Chris; SCHÖN, Donald A. Organizational learning II: theory, method and practice. Reading: Addison-Wesley, 1996.

BEER, Mike. Gerenciando mudança e transição. Rio de Janeiro: Record, 2010.

BRUYNE, Paul de; HERMAN, Jacques; SCHOUTHEETE, Marc de. Dinâmica da pesquisa em ciências sociais: os pólos da prática metodológica. 5. ed. Rio de Janeiro: Francisco Alves, 1991.

BUENO, Wilson da Costa. Comunicação empresarial: políticas e estratégias. São Paulo: Saraiva, 2009.

BUENO, Wilson da Costa. Comunicação empresarial: da rádio peão às mídias sociais. São Bernardo do Campo: Universidade Metodista de São Paulo, 2014.

CARISSIMI, João. Reflexões sobre os processos organizacionais utilizados pelo Relações Públicas na construção da imagem organizacional. In: CONGRESSO BRASILEIRO DE COMUNICAÇÃO, 24., 2001, Campo Grande. Anais... Campo Grande: INTERCOM, 2001. p. 1-12.

CARDOSO, Onésimo de O. Comunicação empresarial versus comunicação organizacional: novos desafios teóricos. Revista de Administração Pública, Rio de Janeiro, v. 40, n. 6, p. 1123-44, 2006.

CROSSAN, Mary M.; LANE, Henry W.; WHITE, Roderick E. An organizational learning framework: from intuition to institution. Academy of Management Review, New York, v. 24, n. 3, p. 522-537, 1999.

DUTRA, Joel Souza. A utopia da mudança das relações de poder na gestão de Recursos Humanos. In: FLEURY, Maria Tereza Leme; FISCHER, Rosa Maria (Org.). Cultura e poder nas organizações. 2. ed. São Paulo: Atlas, 1996. v. 1, p. 155-168.

FLICK, Uwe. Uma introdução à pesquisa qualitativa. 2. ed. Porto Alegre: Bookman, 2004.

GIL, Antonio Carlos. Métodos e técnicas de pesquisa social. São Paulo: Atlas, 1999.

GOODMAN, Michael B.; HIRSCH, Peter B. Corporate communication: strategic adaptation for global practice. Pieterlen: Peter Lang, 2010.

GROUARD, Benoit; MESTON, Francis. Empresa em movimento: conheça os fundamentos e técnicas da gestão de mudança. São Paulo: Negócio, 2001.

HUBER, George P. Organizational learning: the contributing processes and the literatures.

Organization Science, Catonsville, v. 2, n. 1, p. 88-115, 1991.

KUNSCH, Margarida Maria Krohling. Planejamento de relações públicas na comunicação integrada. São Paulo: Summus, 2003.

LIMA, Suzana Maria Valle; BRESSAN, Cyndia Laura. Mudança organizacional: uma introdução. In: LIMA, Suzana Maria Valle (Org.). Mudança organizacional: teoria e gestão. Rio de Janeiro: FGV, 2003. p. 17-64.

MALHOTRA, Naresh K. Pesquisa de marketing: uma orientação aplicada. 4. ed. Porto Alegre: Bookman, 2006. 
MARCHIORI, Marlene. Cultura e comunicação organizacional: um olhar estratégico sobre a organização. 2. ed. São Caetano, SP: Difusão, 2008.

MCDANIEL, Carl D.; GATES, Roger. Pesquisa de marketing. São Paulo: Thomson Learning, 2006.

MEGGINSON, Leon C.; MOSLEY, Donald C.; PIETRI, Paul H. Administração: conceitos e aplicações. São Paulo: Harbra, 1986.

NASSAR, Paulo. Política e Comunicação - A comunicação com pensamento. [2005]. Disponível em: <http://www. reddircom. org/textos/nassar. pdf>. Acesso em: 20 fev. 2015.

NONAKA, Ikujiro; TAKEUCHI, Hirotaka. Criação de conhecimento na empresa: como as empresas japonesas geram a dinâmica da inovação. 13. ed. Rio de Janeiro: Campus, 1997.

PÁDUA, Elisabete Matallo Marchesini de. Metodologia da pesquisa: abordagem teórico-prática. 14. ed. Campinas: Papirus, 2008.

PENTEADO, Jose Roberto Whitaker. Relações públicas nas empresas modernas. Lisboa: Centro do Livro Brasileiro, 1978.

PETTIGREW, Andrew M. Context and action in the transformation of the firm. Journal of Management Studies, Durham, v. 24, n. 6, p. 649-670, 1987.

PETTIGREW, Andrew M. A Cultura das Organizações é Administrável? In: FLEURY, Maria Tereza Leme; FISCHER, Rosa Maria (Org.). Cultura e poder nas organizações. 2. ed. São Paulo: Atlas, 1996. p. 145153.

PIMENTA, Maria Alzira. Comunicação empresarial: conceitos e técnicas para administradores. Campinas: Alínea, 2002.

RABAÇA, Carlos Alberto; BARBOSA, Gustavo Guimarães; SODRE, Muniz. Dicionário de comunicação. São Paulo: Ática, 1987.

SCHEIN, Edgar H. Cultura organizacional e liderança. São Paulo: Atlas, 2009.

SHRIVASTAVA, Paul. A typology of organizational learning systems. Journal of Management Studies, Durham, v. 20, n. 1, p. 7-28, 1983.

SIMON, Herbert. Comportamento Administrativo: estudo dos processos decisórios nas organizações administrativas. Rio de Janeiro: FGV, 1979.

STEINER, George Albert; MINER, John B. Política e estratégia administrativa. Rio de Janeiro: Interciência, 1981.

TORQUATO, Gaudêncio. Tratado de comunicação organizacional e política. 2. ed. São Paulo: Cengage Learning, 2010.

WHITNEY, Margaret A. Analyzing corporate communications policy using ethnographic methods. IEEE Transactions on Professional Communication, Montreal, v. 32, n. 2, p. 76-80, 1989.

YIN, Robert K. Estudo de caso: planejamento e métodos. 3. ed. Porto Alegre: Bookman, 2005. 